\title{
The role of timetable, rolling stock rescheduling and information strategies to passengers in public transport disruptions
}

\section{Conference Poster}

Author(s):

Leng, Nuannuan; Liao, Zhengwen; Corman, Francesco (1)

Publication date:

2020-01

Permanent link:

https://doi.org/10.3929/ethz-b-000402524

Rights / license:

In Copyright - Non-Commercial Use Permitted 


\section{Nuannuan Leng, Zhengwen Liao, Francesco Corman \\ The Role of Timetable, Rolling Stock Rescheduling and Information Strategies to Passengers in Public Transport Disruptions}

\section{Introduction}

\section{Public transport disruptions}

- Malfunctions last more than two hours

- Partial technical components are unavailable

Multi-modal network

- Rail

- Bus/Tram

- Car/ Bike/ Walk

Interaction on passengers

- Timetable

- Rolling stock

- Information

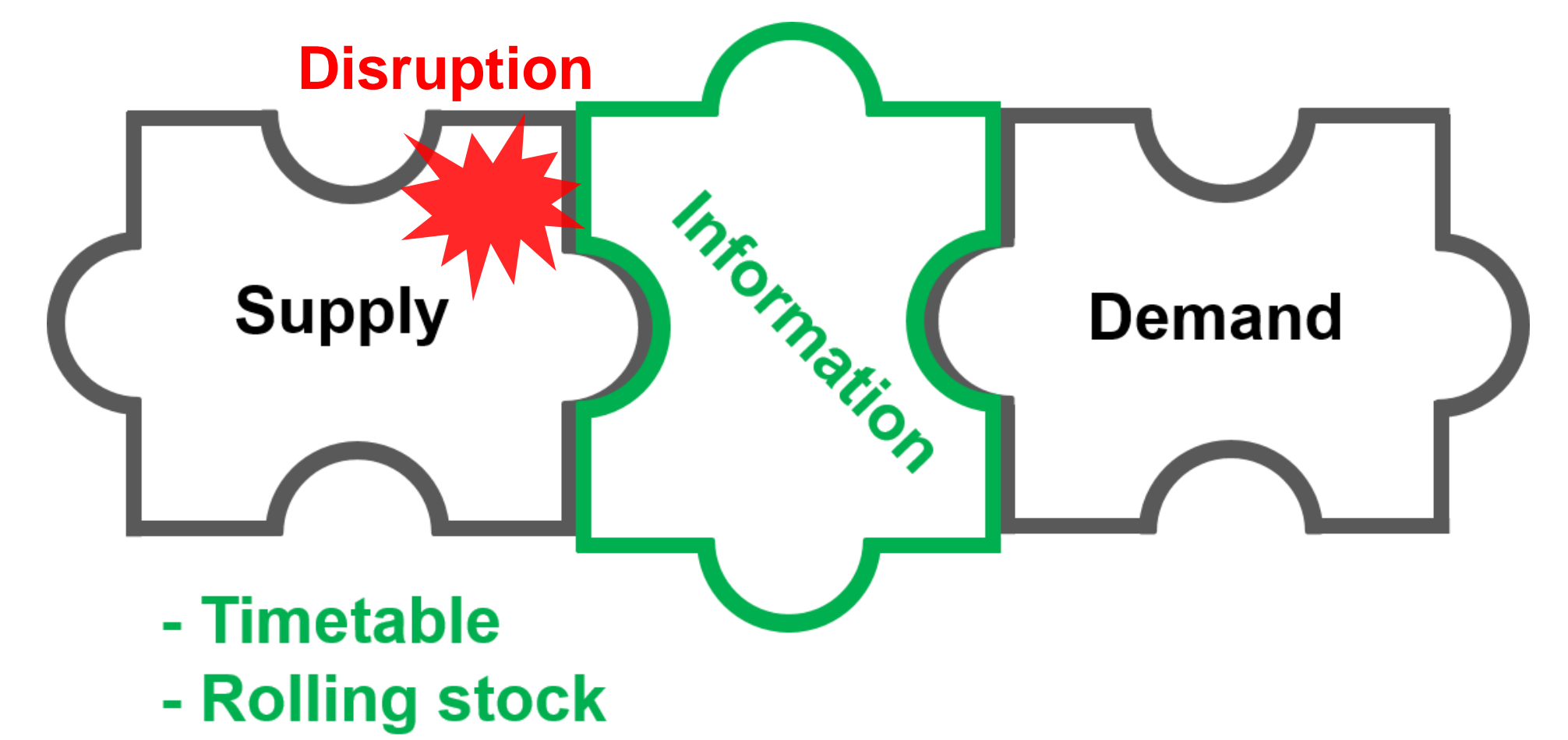

2 Information Strategies and Passengers' Adaptation

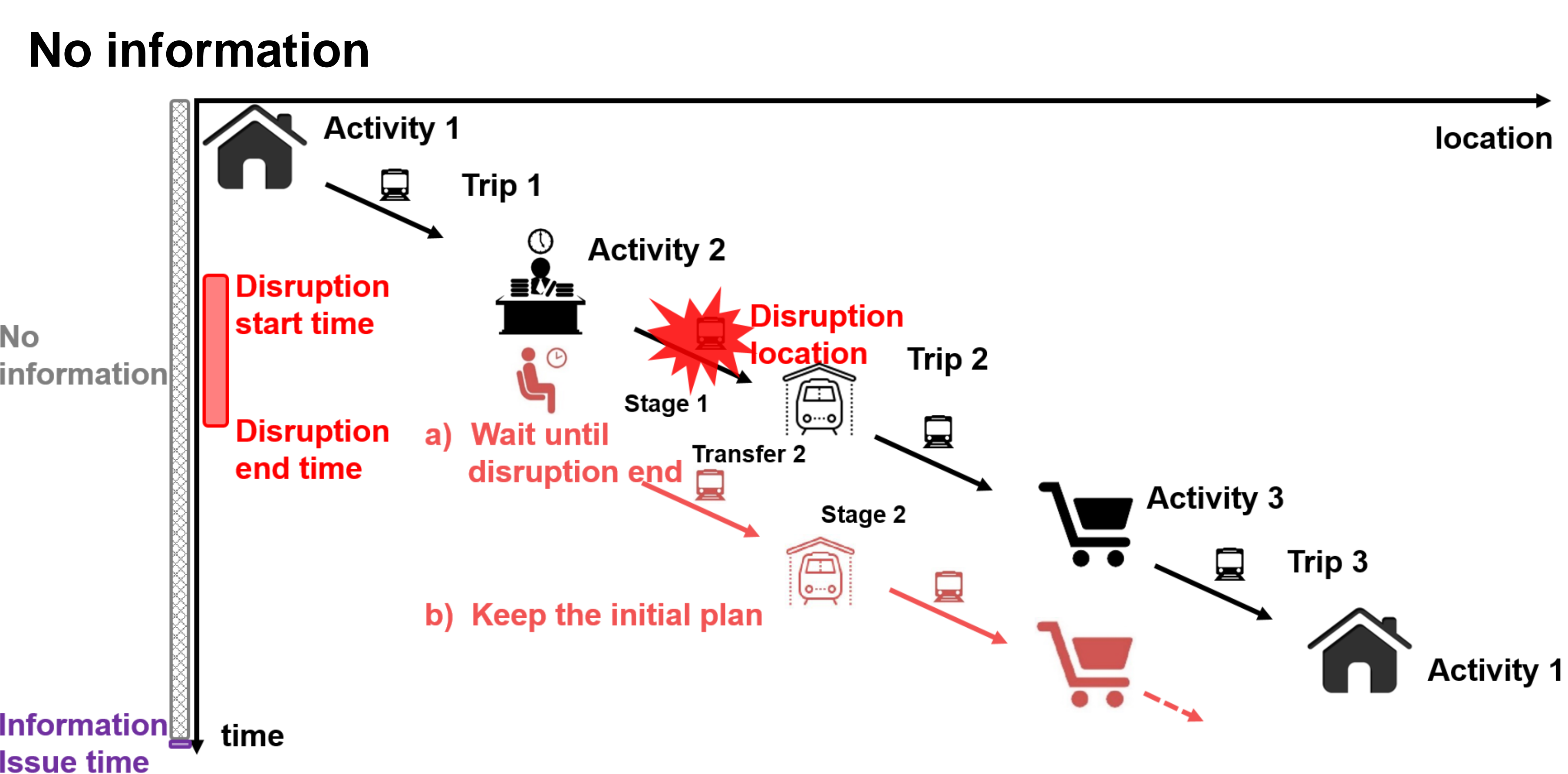

\section{Advance information}

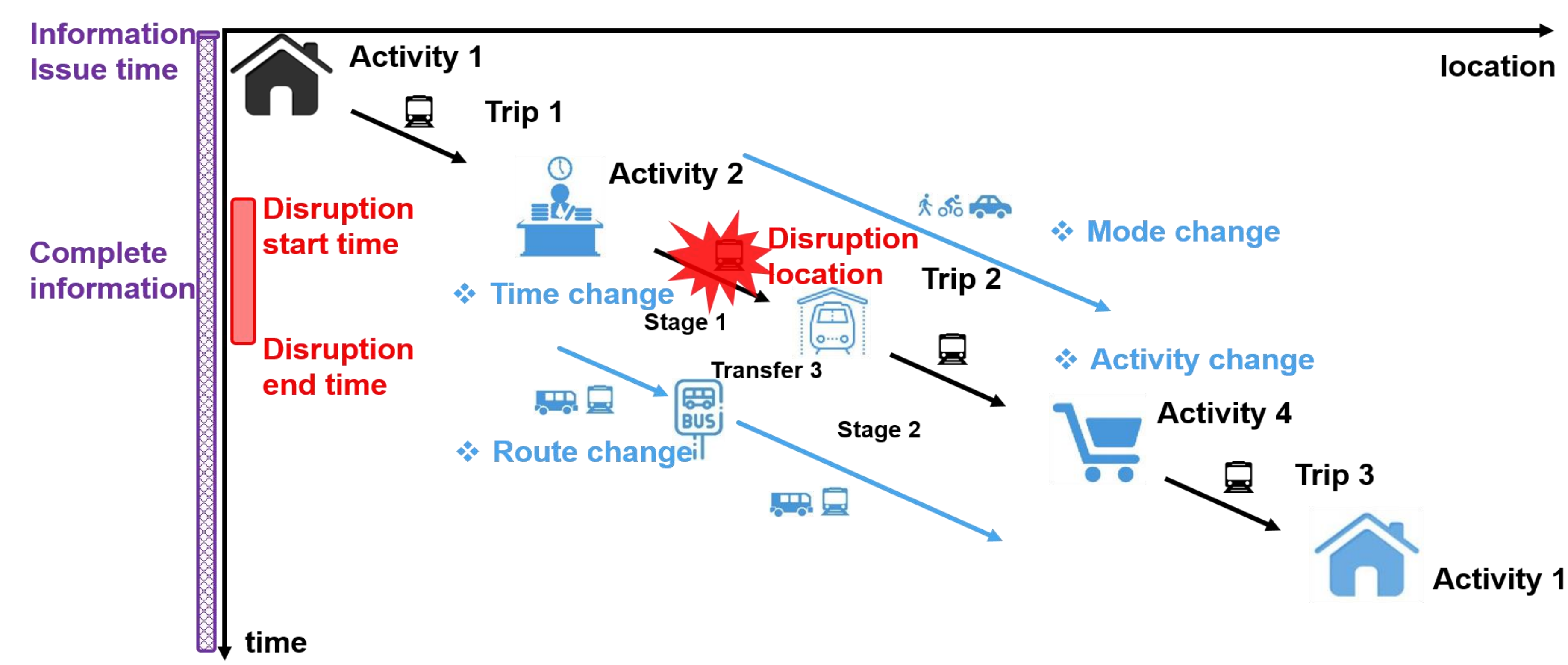

Timely information

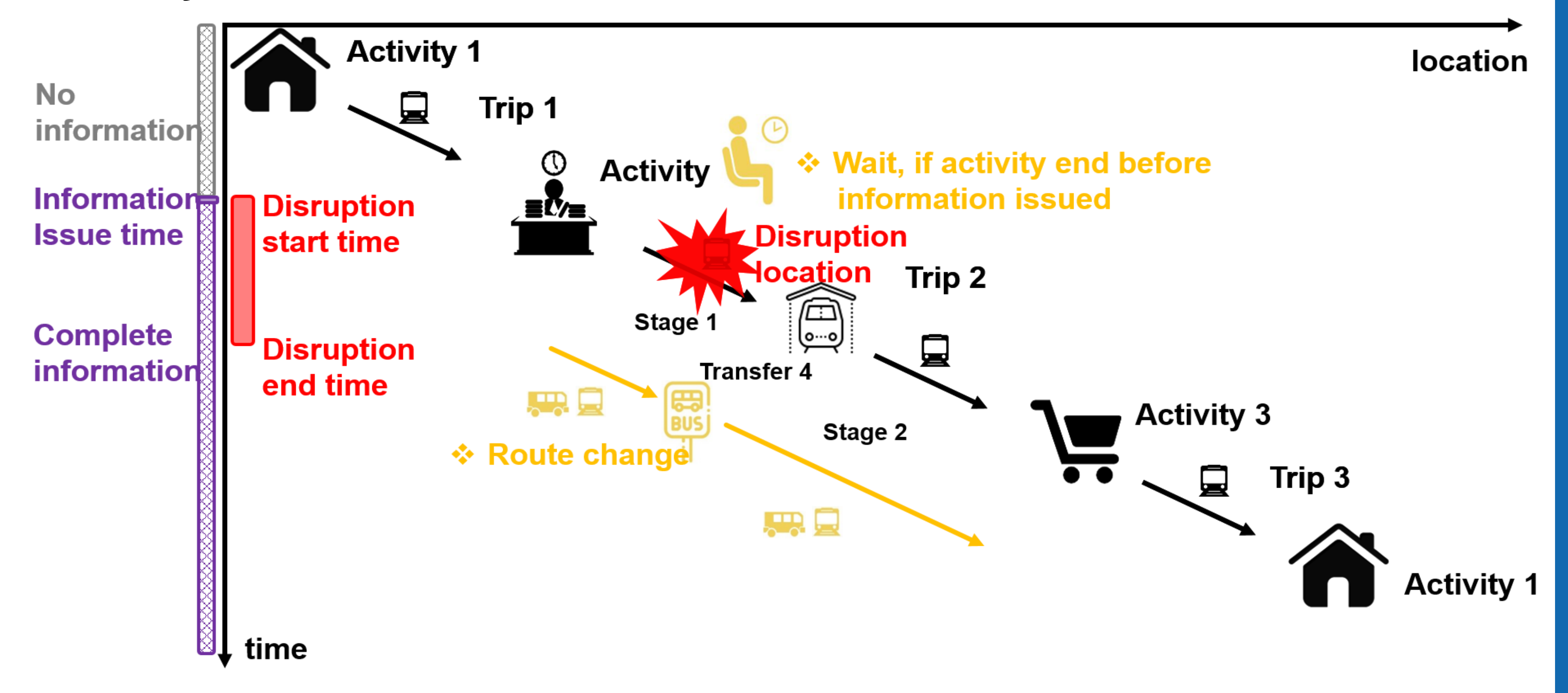

\section{Agent-based Simulation Approach}

The present work uses the MATSim platform for agent-based simulation, with different disposition timetables generated by an optimization model of timetable and rolling stock rescheduling.

- The default MATSim works by reaching an equilibrium solution. (Benchmark)

- No extra replanning, agents wait and postpone initial plans. (No info)

- Alternative routes/ modes/ time/ activities to new equilibrium. (Advance Info)

- Rerouting after disruption starts using within-day replanning. (Timely Info)

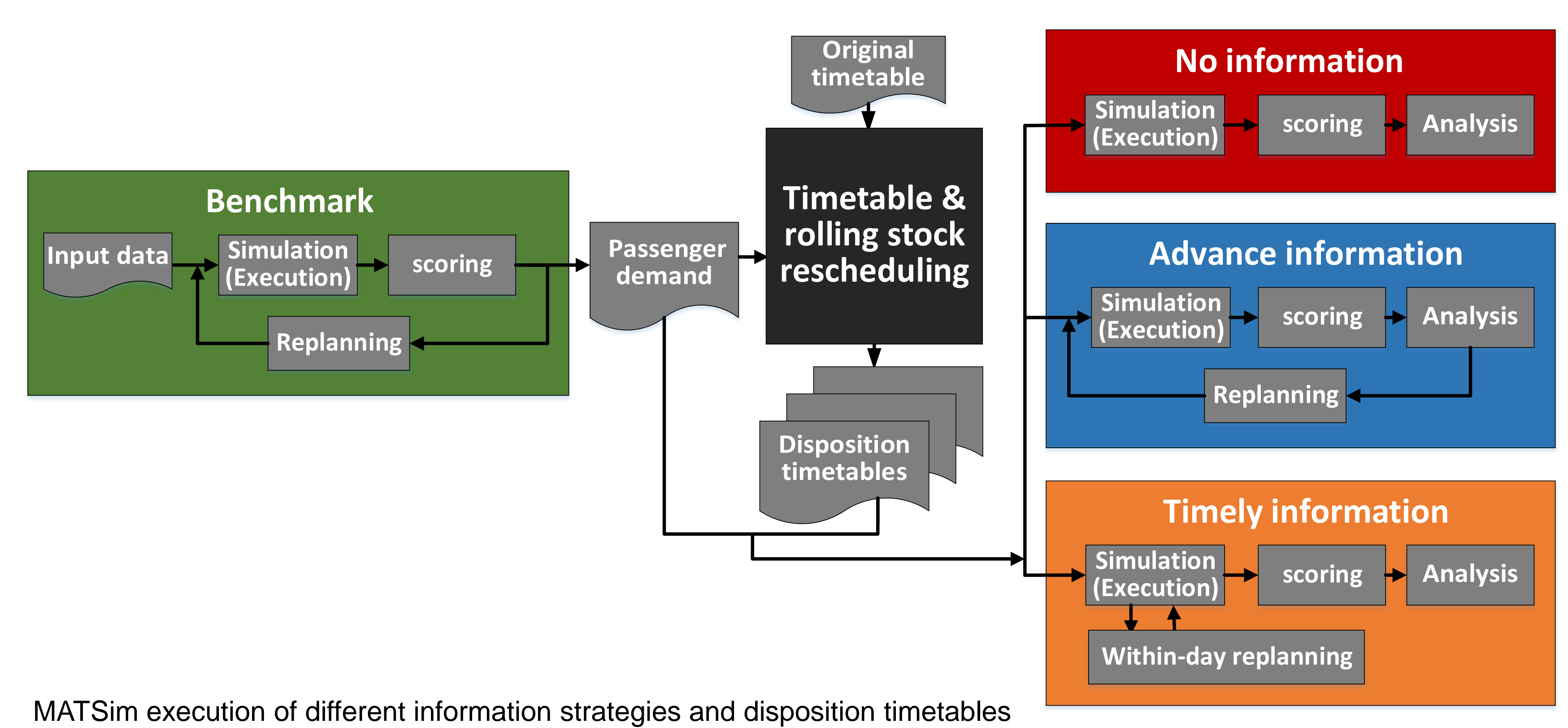

\section{Timetable and Rolling Stock Rescheduling}

A mixed integer programming (MIP) model is applied with train order binary variables, which can be solved by commercial solver. The objective of the optimization model is to minimize the total delay of passengers. The timetable rescheduling includes the strategies retiming, reordering, rerouting, cancellation of train services. In addition, the rolling stock circulation is checked to ensure the feasibility of the disposition timetable. Examples of different schedules are :

- No rerouting vs. Rerouting: rerouting the disrupted train services from "Route 1" to "Route 2".

- Fully cancelled vs. partially cancelled: depending on whether the trains serving the stations beyond station $A$ or station $B$ are cancelled or not.

Rolling stock circulation (partially cancelled): green line shows the feasible rolling stock circulation; otherwise, the services are fully cancelled.
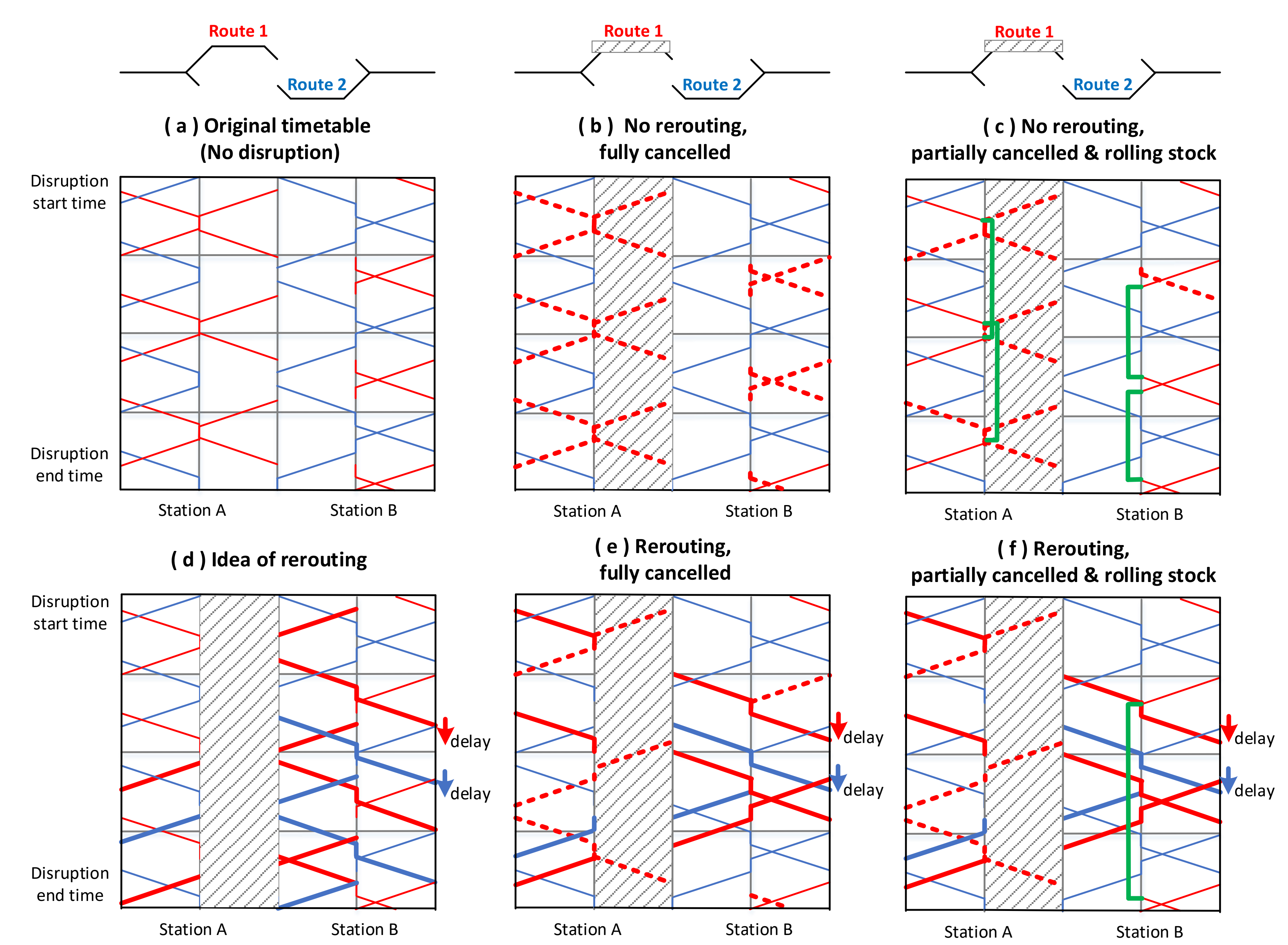


\section{Test Case}

\section{Zürich scenario}

The public transport integration is implemented in the Zürich network, i.e. any multimodal trip between origin and destination is available to public transport users without extra charges.

The assumed rail disruption:

the green and red dashed lines unavailable between 16 and 19 o'clock.

- All long-distance train services can be rerouted on the available undisrupted route;

Local S-bahn services are kept if a feasible rolling stock circulation can be found.

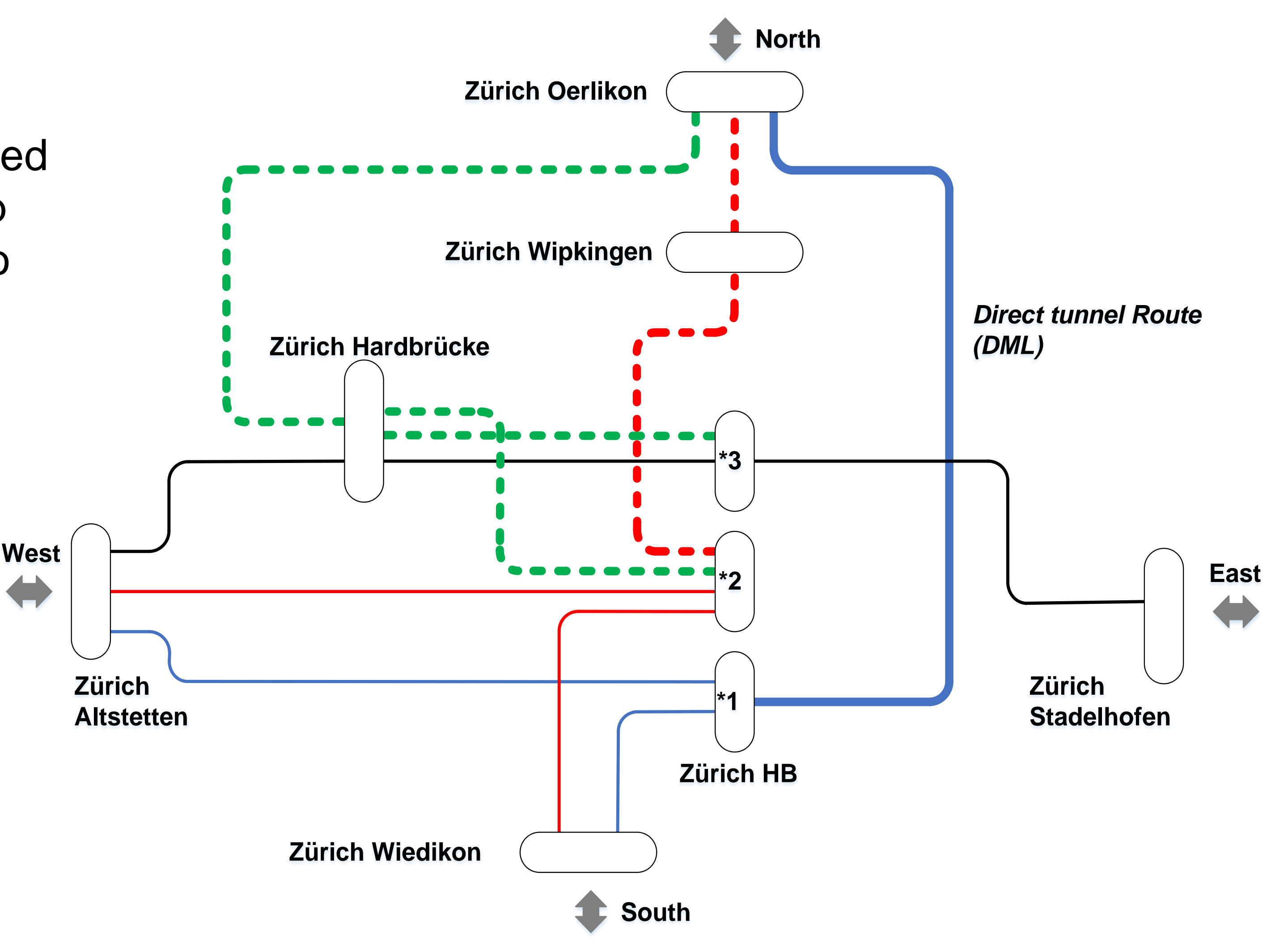

\section{Results}

\section{Schedules}

Due to "rerouting":

$59.5 \%$ of trains can still run on the

alternative route (DML), resulting train Service originally on DML suffer average delay $3.3 \mathrm{~min}$.

"Retime" keeps the trains:

- $4.4 \%$ via Zürich Hardbrücke ( 8.7 min;

- $5.4 \%$ via Zürich Wipkingen (3.7min)

- The total average delay is 3.6 minutes

Due to the feasibility of rolling stock

circulation, some trains are fully cancelled:

- $1.5 \%$ via Zürich Hardbrücke

- $2.7 \%$ via Zürich Wipkingen

\section{Passenger delays and scores}

We classify the agents into three groups:

\begin{tabular}{|c|c|c|c|c|c|}
\hline \multirow{2}{*}{\multicolumn{2}{|c|}{$\begin{array}{c}\text { rescheduling strategies } \\
\text { rolling stock }\end{array}$}} & \multicolumn{2}{|c|}{ no rerouting } & \multicolumn{2}{|c|}{ rerouting } \\
\hline & & \multirow{2}{*}{$\begin{array}{l}\text { fully } \\
100 \%\end{array}$} & \multirow{2}{*}{$\begin{array}{c}\text { partially } \\
1.50 \% \\
\end{array}$} & \multirow{2}{*}{$\begin{array}{c}\text { fully } \\
95.60 \%\end{array}$} & \multirow{2}{*}{\begin{tabular}{|c|} 
partially \\
$1.50 \%$ \\
\end{tabular}} \\
\hline railwa! & $\begin{array}{c}\text { fully } \\
\text { cancelled }\end{array}$ & & & & \\
\hline \multirow{2}{*}{$\begin{array}{l}\text { Zuerich } \\
\text { Hardbrücke }\end{array}$} & $\begin{array}{l}\text { partlally } \\
\text { cancelled }\end{array}$ & 0 & $98.50 \%$ & 0 & $94.10 \%$ \\
\hline & retime & 0 & 0 & $4.40 \%$ & $4.40 \%$ \\
\hline \multicolumn{2}{|c|}{ Avg. train delay [min] } & \multicolumn{2}{|c|}{0} & \multicolumn{2}{|c|}{8.7} \\
\hline & $\begin{array}{l}\text { fully } \\
\text { cancelled }\end{array}$ & $100 \%$ & $62.20 \%$ & $35.10 \%$ & $2.70 \%$ \\
\hline $\begin{array}{l}\text { railway } \\
\text { route via }\end{array}$ & $\begin{array}{c}\text { partially } \\
\text { cancelled }\end{array}$ & 0 & $37.80 \%$ & 0 & $32.40 \%$ \\
\hline \multirow[t]{2}{*}{ Wipkingen } & rerouted & 0 & 0 & $59.50 \%$ & $59.50 \%$ \\
\hline & retime & 0 & 0 & $5.40 \%$ & $5.40 \%$ \\
\hline \multicolumn{2}{|c|}{ Avg. train delay [min] } & \multicolumn{2}{|c|}{0} & \multicolumn{2}{|c|}{3.7} \\
\hline DML & retime & 0 & 0 & $100 \%$ & $100 \%$ \\
\hline \multicolumn{2}{|c|}{ Avg. train delay [min] } & \multicolumn{2}{|c|}{0} & \multicolumn{2}{|c|}{3.3} \\
\hline
\end{tabular}

1) "involved agents": via either Zürich Wipkingen or Zürich Hardbrücke between 16 and 19 o'clock.

- Advance information: rolling stock can be as important, if not more important than rerouting

- Timely information: the benefit of partial cancellation is higher than that of rerouting.

- No information: agents reports limited improvement from rerouting and partial cancellation.

2) "DML agents": via the direct tunnel route (DML) during the defined disruption time.

- 2.7 min more delay due to the "rerouting": agents' delay is just related to train delay, and information plays a minor role.

3) "the others": agents using both either because of multiple trips, or because they need to transfer.

- The largest benefits if operating companies can keep the services beyond the involved stations.

The benefit of information and rerouting services is rather limited.

Agents' average delay (minutes) and average score (\%) due to disposition timetables and information strategies

\begin{tabular}{|c|c|c|c|c|c|c|c|c|c|c|c|}
\hline \multirow{3}{*}{\multicolumn{2}{|c|}{$\begin{array}{c}\begin{array}{c}\text { rescheduling } \\
\text { strategies }\end{array} \\
\text { rolling stock }\end{array}$}} & \multicolumn{5}{|c|}{ Agents' average delay (minutes) } & \multicolumn{5}{|c|}{ Agents' average score (\%) } \\
\hline & & \multicolumn{2}{|c|}{ no rerouting } & \multicolumn{2}{|c|}{ rerouting } & \multirow{2}{*}{$\begin{array}{l}\text { Average, } \\
\text { all } \\
\text { schedules }\end{array}$} & \multicolumn{2}{|c|}{ no rerouting } & \multicolumn{2}{|c|}{ rerouting } & \multirow{2}{*}{$\begin{array}{l}\text { Average, } \\
\text { all } \\
\text { schedules }\end{array}$} \\
\hline & & fully & partially & fully & partially & & fully & partially & fully & partially & \\
\hline \multirow{3}{*}{$\begin{array}{l}\text { involved } \\
\text { agents } \\
(125)\end{array}$} & no info & 137.2 & 137.2 & 128.8 & 128.8 & 133 & -943.6 & -943.6 & -891.8 & -891.8 & -917.7 \\
\hline & $\begin{array}{c}\text { advance } \\
\text { info }\end{array}$ & 16.1 & 5.4 & 8.9 & 2.1 & 8.1 & -76.8 & -32.9 & -46.8 & -14.2 & -42.7 \\
\hline & timely info & 59.4 & 28.5 & 49.8 & 20 & 39.4 & -337.1 & -107.8 & -297.5 & -72.2 & -203.7 \\
\hline \multirow{3}{*}{$\begin{array}{l}\text { DML } \\
\text { agents } \\
(56)\end{array}$} & no info & 0 & 0 & 2.7 & 2.7 & 1.4 & 0 & 0 & -10.7 & -10.7 & -5.4 \\
\hline & $\begin{array}{l}\text { advance } \\
\text { info }\end{array}$ & 0 & 0 & 1.2 & 1.2 & 0.6 & 0 & 0 & -5.8 & -5.8 & -2.9 \\
\hline & timely info & 0 & 0 & 2.7 & 2.7 & 1.4 & 0 & 0 & -10.7 & -13.7 & -6.1 \\
\hline \multirow{3}{*}{ others (30) } & no info & 130.3 & 19 & 121 & 12.5 & 70.7 & -541.2 & -104.5 & -528.9 & -62.5 & -309.3 \\
\hline & $\begin{array}{l}\text { advance } \\
\text { info }\end{array}$ & 11.2 & 7.1 & 9.2 & 6.4 & 8.5 & -34.3 & -18.6 & -24 & -12.2 & -22.3 \\
\hline & timely info & 114.8 & 15 & 108.2 & 10.5 & 62.1 & -528.5 & -56 & -524.2 & -40.1 & -287.2 \\
\hline \multirow{3}{*}{$\begin{array}{l}\text { Average, } \\
\text { all agents } \\
\text { (211) }\end{array}$} & no info & 99.8 & 84 & 94.2 & 78.8 & 89.2 & -636 & -573.9 & -606.4 & -540 & -589.1 \\
\hline & $\begin{array}{l}\text { advance } \\
\text { info }\end{array}$ & 11.1 & 4.2 & 6.9 & 2.5 & 6.2 & -50.4 & -22.1 & -32.7 & -11.7 & -29.2 \\
\hline & timely info & 51.5 & 19 & 45.6 & 14.1 & 32.5 & -274.8 & -71.8 & -253.6 & -52.1 & -163.1 \\
\hline
\end{tabular}

\section{Conclusions}

We study passengers' satisfaction in public transport disruption in a multi-modal network, under different disposition timetables and information strategies, combining an optimization model and agent-based simulation.

1) From the results of a test case in Zürich, there is capacity for many trains to be kept running despite the disruption on an alternative railway route; this allows running more trains against a minor delay (3.6 min on average, including rerouted and original train services). The challenges related to rolling stock still require a minor amount of train services to be cancelled.

2) Our results show that the information strategy is a major driver of delays: the earlier the agents can receive the disposition timetable, the smaller the delay they will suffer in disruption.

3) Being able to partially cancel trains based on a feasible rolling stock circulation is much better for passengers than full cancellation, especially for passengers crossing the disrupted area multiple times. This might require multiple adjustment in the rescheduling process of the company, for additional operation complexity.

4) Train rerouting is able to tradeoff between a large delay for involved agents and a slight delay (2.7 min on average) for agents on the alternative route, assuming agents have enough information to benefit from this change of plans. At system level, the impact of a disruption can be reduced substantially in this way, with a utility impact of the disruption reduced to a fifth only, of the original impact, assuming the realistic timely information strategy.

\section{References}

1. Corman, F. and D'Ariano, A. Assessment of advanced dispatching measures for recovering disrupted railway situations. Transportation Research Record, 2012. 2289.

2. Kroon, L., Maróti, G. and Nielsen, L. Rescheduling of rail rolling stock with dynamic passenger flows. Transportation Science, 2015. 49 (2): 165-184.

3. Dobler, C. and Nagel, K. (2016) Within-Day Replanning. In The Multi-Agent Transport Simulation MATSim, London: Ubiquity Press, pp. 187-200.

4. Rieser-Schuessler, N., Boesch, P M., Horni, A. and Balmer, M. (2016) Zürich. In The Multi-Agent Transport Simulation MATSim, London: Ubiquity Press, pp. 375-378.

\section{Contact}

\section{Nuannuan Leng}

ETH Zürich, IVT

HIL F 14.2, Stefano-Franscini-Platz 5 ,

8093 Zürich, Switzerland

Email: nuannuan.leng@ivt.baug.ethz.ch

Zhengwen Liao

Beijing Jiaotong University

No. 3 Shangyuan Cun, 100044 Beijing, China

Email: zwliao@bjtu.edu.cn

Francesco Corman

ETH Zürich, IVT

HIL F 14.2, Stefano-Franscini-Platz 5 ,

8093 Zürich, Switzerland

Email: francesco.corman@ivt.baug.ethz.ch 